\title{
Isoindole and isomeric heterocyclic donating substituents in ruthenium(II)nitrosyl complexes with large first hyperpolarizabilities and potential two-photon absorption capabilities: a computational approach
}

\author{
Valerii Bukhanko $^{\mathrm{a}, \mathrm{b}}$, Isabelle Malfant ${ }^{\mathrm{a}}$, Zoia Voitenko ${ }^{\mathrm{b}}$, Pascal G. Lacroix ${ }^{\mathrm{a} *}$ \\ a Laboratoire de Chimie de Coordination du CNRS (UPR 8241), \\ 205 route de Narbonne, 31077 Toulouse, France \\ ${ }^{\mathrm{b}}$ Department of Chemistry, Taras Shevchenko National University of Kyiv, \\ Volodymyrska Street, 64/13, Kyiv 01601, Ukraine \\ contactinge-mail pascal.lacroix@lcc-toulouse.fr
}

Keywords: ruthenium-nitrosyl, isoindole, two-photon absorption, DFT computations.

A set of 22 ruthenium nitrosyl complexes of general formula $\left[\mathrm{Ru}^{\mathrm{II}}(\mathrm{L}) \mathrm{Cl}_{2}(\mathrm{NO})\right]^{+}$is investigated computationally by the density functional theory. L is a terpyridine ligand substituted by different isomers of formula $\mathrm{C}_{12} \mathrm{H}_{8} \mathrm{~N}$, either indole, isoindole, or carbazole, proposed as alternative donors to the electron-rich fluorene substituent. The computed resulting nonlinear optical (NLO) properties are found to strongly depend on the isomer. While the ruthenium complexes exhibit modest efficiencies at the second-order (two-photon absorption) level, some of the $\mathrm{R}$ isomers lead to complexes of enhanced capabilities in first order $(\beta)$ nonlinear optics. The synthetic feasibility of these ligands is discussed.

\section{Introduction}

The prediction by Göppert-Mayer in 1931 [1] that a molecule could absorb two photons simultaneously within a so-called twophoton absorption (TPA) process, was demonstrated experimentally in 1961 [2] and has gradually emerged to become the most promising of the nonlinear optical (NLO) properties. Indeed, several reviews have witnessed the considerable attention devoted to this intriguing phenomenon in relation to its relevant applications either as advanced optical materials, or in various fields of life sciences, such as biomedical imaging and photodynamic therapy [3-7].

Photodynamic therapy is a non-surgical therapy based on photosensitizers, which are innocent molecules in the dark, capable to induce damage upon optical irradiations. Their toxicity has mostly been due to singlet oxygen generated by energy transfer from the excited state of the photosensitizer to dioxygen [8]. Nevertheless, alternative species have recently been envisioned. For instance, nitric oxide (NO), which plays a key role in numerous 
physiological and pathological processes such as blood pressure regulation, immune response, neurotransmission, or respiration [9], has also been recognized for its cytotoxic activity in tumor cells by apoptosis [10], and therefore the search for efficient $\mathrm{NO}$ - donor has become an active research domain, especially in the class of ruthenium(II) nitrosyl complexes [11-14].

We have recently reported on two substituted cis- and trans-terpyridinenitrosylruthenium(II) complexes (A and $\mathbf{B}$, Scheme 1) capable to release $\mathrm{NO} \cdot$ with good quantum yields, under irradiation at $\lambda=405 \mathrm{~nm}[15]$.

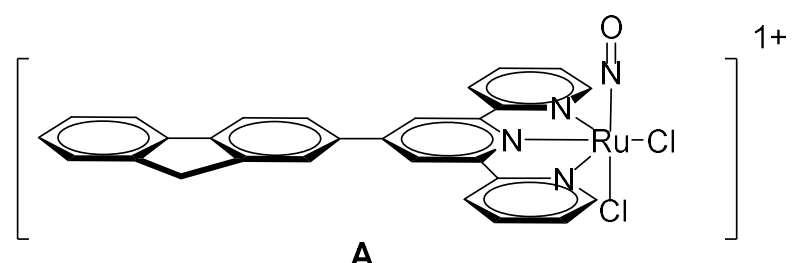

A

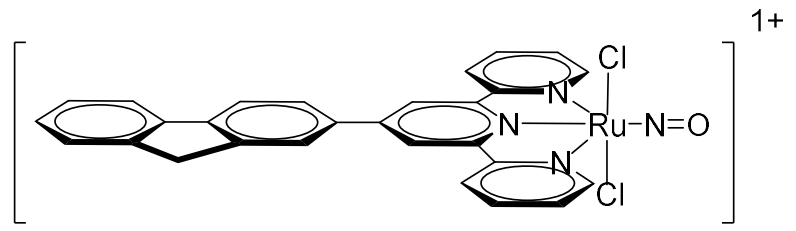

B

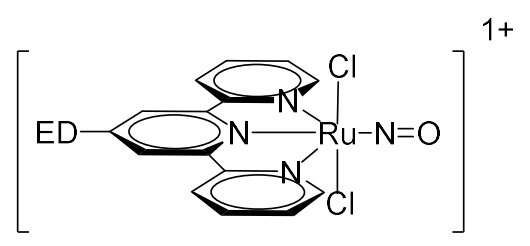

C

Scheme 1. Ruthenium(II) nitrosyl complexes with terpyridine-based ligand
This effect should benefit from the TPA phenomenon which is proportional to the square of the light intensity $\left(\propto \mathrm{I}^{2}\right)$ and therefore is confined to the focal volume, a situation which prevents undesirable collateral photochemical damages. Additionally, while most NO donors require to be irradiated in the $400-600 \mathrm{~nm}$ wavelengths domain, the use of TPA at double wavelength allows working in the $600-1300 \mathrm{~nm}$ therapeutic window of relative transparency of the biological media [16]. Owing to these appealing perspectives, the issue of designing terpyridinenitrosylruthenium(II) complexes exhibiting sizeable TPA capabilities arises naturally.

The TPA response of a molecule can be understood in the context of the TPA crosssection $\left(\sigma_{\mathrm{TPA}}\right)$ of each of its individual $g \rightarrow e_{\mathrm{i}}$ electronic transitions towards its $i^{\text {th }}$ excited state. $\sigma_{\text {TPA }}$ is the two-photon equivalent of the onephoton absorption extinction coefficient $\left(\varepsilon_{\mathrm{OPA}}\right)$, and is related to the imaginary part of the second hyperpolarizability $(\operatorname{Im} \gamma)$, as follows [17]:

$$
\sigma_{T P A}=\frac{8 \pi^{2} \hbar \omega^{2}}{n^{2} c^{2}} L^{4} \operatorname{Im} \gamma
$$

where $\omega$ is the laser frequency, $n$ the refractive index, $c$ the velocity of light in vacuum, and $L$ the local field factor, and $\gamma$ the second-order hyperpolarizability defined from the Taylor development of the molecular polarization $(\mu)$ induced by an external electric field $(E)$ as: 


$$
\mu=\mu_{0}+\alpha E+\beta E^{2}+\gamma E^{3}+\cdots
$$

where $\mu_{0}$ is the dipole moment, $\alpha$ the polarizability, $\beta$ and $\gamma$ the first and second order hyperpolarizabilities. Two kinds of molecules have gradually emerged as promising TPA candidates: dipolar and quadrupolar (centrosymmetric) molecules [3-7]. In the case of the present investigation, and while the complete understanding of the quantum mechanism involved in the NO release is still being discussed by theorists [16], an electronic transition towards the strong withdrawing nitrosyl ligand has been identified as the first step of the NO release process. If this transition has to be TPA active, it seems therefore natural to target the NO donor in the class of "pushpull" 1-dimensional chromophores, in which the electron withdrawing pole (NO) finds its electron donating (ED) counterpart on an electron-rich substituted terpyridine ligand. This situation leads to the target molecules C (Scheme 1).

In the case of long range delocalized push-pull effects, the expression of $\sigma_{\mathrm{TPA}}$ can be tentatively approached by a simple two-level model involving the current $g \rightarrow e$ transition. as follows [6]:

$$
\sigma_{T P A} \approx \frac{16{ }^{2} f\left(\mu_{e e}-\mu_{g g}\right)^{2}}{5 \hbar^{2} c^{2} \Gamma E_{g e}}
$$

In this equation, $E_{g e}$ is the energy of the transition, $f$ its oscillator strength, $\mu_{g g}$ and $\mu_{e e}$ the dipole moments in the ground and excited states, respectively. It is interesting to point out that equation 4 is reminiscent of the simplified but widely used "two-level" description of the intrinsic $\beta$ (equation 2), denoted $\beta_{0}$ which relates the property to the contribution of a single $g \rightarrow e$ transitions as follows [19]:

$$
\beta_{0} \approx \frac{3 e^{2} \hbar f\left(\mu_{e e}-\mu_{g g}\right)}{2 m\left(E_{g e}\right)^{3}}
$$

It is noteworthy that expressions (3) and (4) involve the same parameters $\left(\mu_{e e}-\mu_{g g}, f\right.$, and $\left.E_{g e}\right)$. These similarities imply that a promising strategy in the search for molecules with high $\sigma_{\text {TPA }}$ values should be to target molecules designed for high $\beta$ values for which the two-level model $\left(\beta_{0}\right)$ has long been applied successfully [20].

In the present report, various $\left[\mathrm{Ru}{ }^{\mathrm{II}}(\mathrm{R}\right.$ terpy $\left.(\mathrm{Cl})_{2}(\mathrm{NO})\right]^{+} \quad$ complexes bearing $\mathrm{R}$ donating substituents are investigated computationally in a research effort aimed at targeting suitable candidates for high $\beta$ values, and therefore potentially enhanced TPA response. In the reference compound $\mathbf{B}$, the fluorenyl substituent (D, Scheme 2) acts as the electron donor in the charge transfer transitions [15]. Nevertheless, the donating capabilities of D are rather moderate. The introduction of an electron rich center delocalized within the polycyclic structure should be a means of guaranteeing an enhancement of the donating capabilities of $\mathbf{D}$. For instance, the introduction of a nitrogen atom in the central node leads to 
the pyrido[2,1-a]isoindole species, in which a $14 \pi$-electrons path of delocalization can provide a sizeable push-pull effect either towards position 6 or 4 (E and $\mathbf{F}$ respectively, Scheme 2).
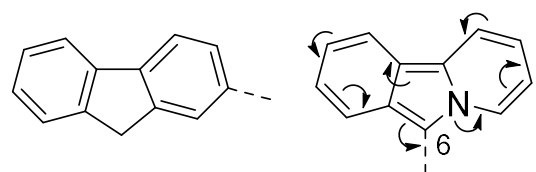

E

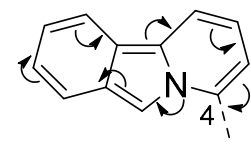

$\mathbf{F}$

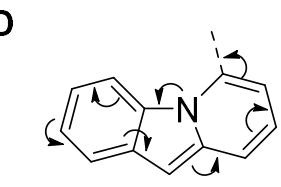

G

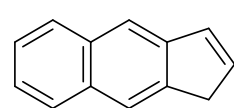

H
Scheme 2. Polycyclic structures with donating capabilities.

It was previously shown by theoretical calculations using several approaches and then proved with X-ray diffraction analysis and mass spectrometry that the nitrogen atom of the isoindole is strongly involved in the $\pi$ delocalized structure $[21,22]$. Owing to an electron-rich o-quinonic structure, isoindole can act as an efficient electron-donating moiety. Joining an additional pyridine ring to an isoindole core evolves $10 \pi$ electron systems to $14 \pi$ systems along with conservation of a conjugation over the entire extend of the rings [23]. The indole species G (Scheme 2) could also be envisioned as an alternative species, and more generally, any nitrogen-based heterocycle constructed from the benz[f]indene skeleton $\mathbf{H}$ could also be encompassed in this investigation. Altogether, this approach leads to a total of 107 potential isomers. The investigation will be extended to the reference fluorene substituent $\mathbf{D}$ present on the terpyridine ligand in complex $\mathbf{A}$ and $\mathbf{B}$, for the sake of a relevant quantification.

The systematic screening of nitrogen heterocycles will be presented first. Then the first hyperpolarizabilities, $\sigma_{T P A}$, and dominant UV-vis parameters computed with the framework of the density functional theory (DFT) for the resulting species will be discussed in order to target the most promising of these species for further NLO applications at the quadratic or cubic level.

\section{Computational methods}

The ruthenium complexes investigated in the present study were fully optimized in gas phase using the Gaussian-09 program package [24] within the framework of the Density Functional Theory (DFT). The double- $\zeta$ basis set $6-31 G^{*}$ was used for all atoms except the heavy ruthenium atom, for which the LANL2DZ basis set was applied to account for relativistic effects [25]. To be consistent with our previous report [15], and in agreement with a previous investigation of ruthenium-nitrosyl by Mascharak [26], we have selected the hybrid functional B3PW91 for the optimization. B3PW91 has been shown to outperform other hybrid functionals (e.g. B3LYP) and pure functionals (e.g. PW91) in numerous cases of ruthenium complexes, especially when back bonding ligands (like NO) are present [26,27]. 
The vibrational analyses were performed at the same level to verify that the stationary points correspond to minima on the potential energy surfaces. The UV-visible electronic spectra were then computed at the CAM-B3LYP/6$31 \mathrm{G}^{*}$ level, which was selected for its good efficiency to reproduce experimental transition energies within an uncertainty $<0.5 \mathrm{eV}$ in the case of the reference molecules $\mathbf{A}$, and $\mathbf{B}$ [15]. For each molecule under investigation, the two possible conformers resulting from the rotation around $\sigma$-bond between the fused heterocyclic system and the $\mathrm{C}=\mathrm{C}$ double bond of the ethenyl linkage were considered (vide infra). The most stable one was selected by comparison of their Gibbs free energy $\left(\Delta \mathrm{G}^{\circ}\right)$.

The total hyperpolarizabilities $(\beta)$ were computed at the B3PW91/6-31G** level, in which $p$ polarization functions are used on hydrogen atoms. The ten independent $\beta_{i j k}$ tensor components were computed by the derivative procedure implemented in Gaussian09 , according to the following equation:

$$
\beta_{i j k}=-\left(\frac{\partial^{3} W}{\partial E_{i} \partial E_{j} \partial E_{j}}\right)_{E=0}
$$

where $W$ is the energy and $E$ the electric field. This expression is only valid for the static field limit, which corresponds to the Kleinman conditions [28]. We have checked that $\beta$ is not field dependent in the range of computations.

The final $\beta$ value is given as the magnitude of the $\beta$ vector $\left(=\sqrt{\beta_{x}^{2}+\beta_{y}^{2}+\beta_{z}^{2}}\right)$.
The vectorial component $\beta_{i}$ is computed from the tensor components as: $\beta_{i}=\beta_{i x x}+\beta_{i y y}+$ $\beta_{i z z}$

\section{Results and discussion}

\section{Selection of the candidates}

Owing to the large number of isomers (107), the only ones selected here were those having the whole (14) $\pi$-electrons potentially involved in the path of conjugation from the nitrogen atom to the linkage towards the terpyridine, for a better comparison of their induced push-pull capabilities. The different structures can be gathered in two groups depending on the position of the 5-membered ring either on the side (6-6-5) or in the center (6-5-6) of the molecule (Note that, for the sake of simplification, the 3-fused rings or bent structures were discarded from the selection). Each system is further identified by the position of the nitrogen atom, and by that of the linkage. Depending on the place of the nitrogen in the rings, and to ensure that a tertiary amine is present in any case, any - NH group is replaced by $-\mathrm{NMe}$. Finally, an ethenyl $(-\mathrm{CH}=\mathrm{CH}-)$ unit is inserted between the polyaromatic system and the terpyridine moiety to reduce the steric hindrance in the molecules. This modification is achieved in order to decrease undesirable torsion angles and to enhance the conjugation of $\pi$-bonds. Such alteration allows us to compare the real influence of the isomeric heterocycles on optical and electronic properties of the 
complexes. The resulting $\mathbf{1}-\mathbf{2 2}$ candidates are presented in Scheme 3, with the reference complex $\mathbf{B}$ ' related to $\mathbf{B}$, in which the ethenyl

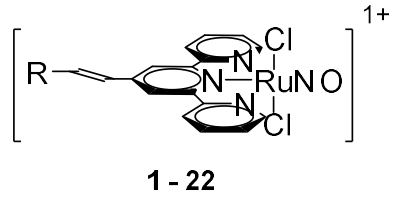

6-6-5-membered tricyclic rings

$\mathrm{N}$ in the 5-membered ring

$\mathrm{N}$ in a 6 -membered ring

1: $\mathrm{R}=$

6: $\mathrm{R}=\mathrm{i}$

2: $\mathrm{R}=$

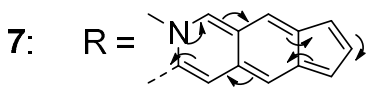

3: $\mathrm{R}=\mathrm{S}$

8: $\mathrm{R}=$

4: $R=\sqrt{2}$

9: $\mathrm{R}=\mathrm{r}$

5: $\quad \mathrm{R}=$
10: $R=$

11: $R=$ unit is introduced for a better consistency with the 22 molecules under investigation.
B': $\mathrm{R}=$

6-5-6-membered tricyclic rings

$\mathrm{N}$ in the 5-membered ring

$\mathrm{N}$ in a 6-membered ring

12:<smiles></smiles>

17: $\mathrm{R}=$

13:

$R=r a t$

18: $R=2=1$

14: $R=$<smiles></smiles>

19: $\mathrm{R}=\mathrm{N}$

15 :

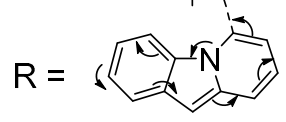

20:

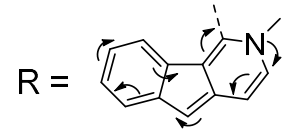

16

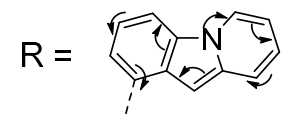

21

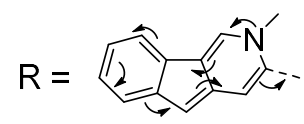

22

Scheme 3: 6-6-5-membered tricyclic rings $(\mathbf{1}-\mathbf{1 1})$ and 6-5-6-membered rings $(\mathbf{1 2}-\mathbf{2 2})$ complexes, and reference derivative B'.

\section{Computed geometries}

The details for the computed coordination spheres of the 23 complexes under investigations are provided in Table 1, and compared to that of the previously reported complex B.

The computed coordination spheres appear similar in any case, with largest relative bond lengths difference of $0.6 \%$ observed at the Ru-N (central pyridine) between 7 (1.993 $\AA)$ and 12 (2.006 $\AA)$. The agreement with the experimental data available [15] is found satisfactory, with a general shortening of bond lengths in the X-ray geometries, from those computed by DFT. 


\begin{tabular}{|c|c|c|c|c|c|}
\hline compound & $\mathrm{Ru}-\mathrm{N}(\mathrm{NO})$ & $\begin{array}{c}\mathrm{Ru}-\mathrm{N} \\
\text { (central pyridine) }\end{array}$ & $\begin{array}{c}\mathrm{Ru}-\mathrm{N} \\
\text { (lateral pyridines) }\end{array}$ & $\mathrm{Ru}-\mathrm{Cl}$ & $\mathrm{Cl}-\mathrm{Ru}-\mathrm{Cl}$ \\
\hline 1 & 1.760 & 1.994 & 2.087 & 2.405 & 172.5 \\
\hline 2 & 1.759 & 2.002 & 2.087 & 2.401 & 171.8 \\
\hline 3 & 1.758 & 2.001 & 2.088 & 2.401 & 171.9 \\
\hline 4 & 1.759 & 1.995 & 2.087 & 2.404 & 172.4 \\
\hline 5 & 1.759 & 1.998 & 2.087 & 2.403 & 172.1 \\
\hline 6 & 1.763 & 1.994 & 2.086 & 2.405 & 172.5 \\
\hline 7 & 1.761 & 1.993 & 2.086 & 2.406 & 172.6 \\
\hline 8 & 1.764 & 1.998 & 2.085 & 2.404 & 172.1 \\
\hline 9 & 1.758 & 2.005 & 2.087 & 2.400 & 171.4 \\
\hline 10 & 1.760 & 1.999 & 2.087 & 2.402 & 172.0 \\
\hline 11 & 1.760 & 2.000 & 2.087 & 2.402 & 171.9 \\
\hline 12 & 1.758 & 2.006 & 2.088 & 2.399 & 171.4 \\
\hline 13 & 1.759 & 2.000 & 2.087 & 2.402 & 171.9 \\
\hline 14 & 1.759 & 1.996 & 2.087 & 2.404 & 172.5 \\
\hline 15 & 1.759 & 2.003 & 2.087 & 2.401 & 171.6 \\
\hline 16 & 1.758 & 2.001 & 2.087 & 2.402 & 171.9 \\
\hline 17 & 1.759 & 2.003 & 2.087 & 2.400 & 171.6 \\
\hline 18 & 1.760 & 1.994 & 2.086 & 2.405 & 172.6 \\
\hline 19 & 1.760 & 1.996 & 2.086 & 2.404 & 172.3 \\
\hline 20 & 1.759 & 2.005 & 2.087 & 2.400 & 171.4 \\
\hline 21 & 1.760 & 1.998 & 2.087 & 2.402 & 172.1 \\
\hline 22 & 1.760 & 1.996 & 2.087 & 2.404 & 172.4 \\
\hline B' & 1.760 & 2.004 & 2.088 & 2.400 & 171.6 \\
\hline B & $1.759(6)$ & $2.001(5)$ & $\begin{array}{l}2.081(6) \\
2.073(6)\end{array}$ & $\begin{array}{l}2.348(2) \\
2.364(2)\end{array}$ & $172.58(6)$ \\
\hline
\end{tabular}

Table 1: Main bond lengths (in $\AA$ ) and angles (in ${ }^{\circ}$ ) in the computed coordination spheres. The values for B are experimental X-ray data (ref 15), provided as references.

"Push-pull”effects in complexes 1 - 22

The relevant NLO parameters $\left(\beta, \beta_{0}\right.$, and $\left.\sigma_{\text {TPA }}\right)$ of the 22 selected isomers are gathered in Table 2. It is important to note that, while $\beta$ the only ones providing significant $\beta_{0}$ values. corresponds to the quadratic NLO response of To further simplify the understanding, $\beta_{0}$, and 
$\sigma_{\mathrm{TPA}}$ are expressed as relative values, those of the $\mathbf{B}^{\prime}$ reference system being taken as 1 .

Table 2 NLO quadratic ( $\beta$ in $10^{-30} \mathrm{~cm}^{5} \mathrm{esu}^{-1}$, and relative $\beta_{0}$ related to the $\mathrm{i}^{\text {th }}$ transition) and cubic (relative $\sigma_{\mathrm{TPA}}$ crosssection related to the $\mathrm{i}^{\text {th }}$ transition) for $\mathbf{1 - 2 2}$, and $\mathbf{B}$ ' for which $\beta_{0}$ and $\sigma_{\mathrm{TPA}}$ are set at 1 , and used as references.

\begin{tabular}{|c|c|c|c|c|}
\hline compound & $\beta$ & \# exited state & relative $\beta_{0}$ & relative $\sigma_{\mathrm{TPA}}$ \\
\hline 1 & 487.2 & $i=1$ & 0.83 & 0.24 \\
\hline \multirow[t]{2}{*}{2} & 732.3 & $\mathrm{i}=1$ & 0.96 & 0.56 \\
\hline & & $i=5$ & 0.63 & 0.57 \\
\hline 3 & 450.4 & $\mathrm{i}=1$ & 1.32 & 1.01 \\
\hline 4 & 475.8 & $\mathrm{i}=1$ & 0.90 & 0.30 \\
\hline 5 & 502.3 & $\mathrm{i}=1$ & 1.34 & 0.48 \\
\hline 6 & 2709.9 & $\mathrm{i}=1$ & 0.58 & $<0.01$ \\
\hline 7 & 1539.5 & $\mathrm{i}=1$ & 2.82 & 0.57 \\
\hline 8 & 2751.7 & $\mathrm{i}=1$ & 3.34 & 0.09 \\
\hline 9 & 301.4 & $\mathrm{i}=1$ & 0.29 & 0.15 \\
\hline 10 & 1130.0 & $\mathrm{i}=1$ & 0.96 & 0.10 \\
\hline 11 & 733.2 & $\mathrm{i}=1$ & 1.37 & 0.03 \\
\hline \multirow[t]{2}{*}{12} & 233.1 & $i=3$ & 0.48 & 0.52 \\
\hline & & $i=5$ & 0.15 & 0.21 \\
\hline 13 & 754.2 & $\mathrm{i}=1$ & 1.43 & 0.48 \\
\hline 14 & 376.1 & $\mathrm{i}=1$ & 0.74 & 0.24 \\
\hline 15 & 540.4 & $\mathrm{i}=1$ & 0.85 & 0.28 \\
\hline 16 & 553.3 & $\mathrm{i}=1$ & 1.04 & 0.53 \\
\hline 17 & 975.3 & $\mathrm{i}=1$ & 0.97 & 0.28 \\
\hline 18 & 855.1 & $\mathrm{i}=1$ & 1.30 & 0.27 \\
\hline \multirow[t]{2}{*}{19} & 782.8 & $\mathrm{i}=1$ & 0.94 & 0.08 \\
\hline & & $\mathrm{i}=8$ & 0.19 & 0.10 \\
\hline \multirow[t]{2}{*}{20} & 328.8 & $\mathrm{i}=1$ & 0.21 & 0.03 \\
\hline & & $i=7$ & 0.21 & 0.11 \\
\hline 21 & 1289.8 & $\mathrm{i}=1$ & 1.48 & 0.34 \\
\hline \multirow[t]{2}{*}{22} & 1041.2 & $i=1$ & 1.11 & 0.25 \\
\hline & & $\mathrm{i}=8$ & 0.54 & 0.43 \\
\hline B' (reference) & 463.2 & $i=4$ & 1 & 1 \\
\hline
\end{tabular}

The first thing to observe in the Table is capabilities of the electron-rich heterocyclic that the $\beta$ values of compounds $\mathbf{1 - 2 2}$ are amines. Nevertheless, this tendency is not generally larger than that of the reference observed in compounds 3, 9, 12, 14, and 20, compound B'. This confirms the donating which emphasizes the role of the conjugation 
path, although the delocalization over the whole extent of the $\pi$-system is present in any cases.

More generally, what strikes from the examination of Table 2 is the magnitude of the computed values, for isomeric species containing the same acceptor (NO), conjugated path length (arylethenyl-substituted terpyridine) and closely related donors (tertiary amines). Indeed, $\beta$ ranges from 233.1 (12) to $2751.7(\mathbf{8}) \times$ $10^{-30} \mathrm{~cm}^{5} \mathrm{esu}^{-1}, \beta_{0}$ from $0.21(\mathbf{2 0})$ to $3.34(\mathbf{8})$, and $\sigma_{\mathrm{TPA}}$ from $<0.01(\mathbf{6})$ to $1.01(\mathbf{3})$.

Computed $\beta$ values around $100 \times 10^{-30}$ $\mathrm{cm}^{5} \mathrm{esu}^{-1}$ are rather common in conjugated organic species [29]. Values larger than $1000 \times$ $10^{-30} \mathrm{~cm}^{5} \mathrm{esu}^{-1}$ have occasionally be found in the case of donor-acceptor effects extended over a path of conjugation in the range of 20 bonds [30]. Few experimental data have been reported in which the withdrawing core is based on a $\mathrm{Ru}^{\text {II }}$ center. Representative examples are provided in Figure 1. They are associated with typical $\beta$ values around $300-50010^{-30} \times \mathrm{cm}^{5} \mathrm{esu}^{-1}$. Therefore, the large values computed here $(\beta=$ 2709.9 and $2751.7 \times 10^{-30} \mathrm{~cm}^{5}$ esu $^{-1}$ for $\mathbf{6}$ and $\mathbf{8}$, respectively) may be accurate and therefore deserve further analyses.

Following the conventional picture of donor-acceptor chromophores, increasing $\beta$ would imply increasing the push-pull effect from the heterocyclic amine towards the $\mathrm{Ru}(\mathrm{NO})$ core. This should normally lead to an increase of the electron transfer to an antibonding $\pi^{*}$ orbital of the nitrosyl ligand, with the outcomes of a decrease of the $v \mathrm{NO}$ stretching frequency. This is illustrated in Figure 2.

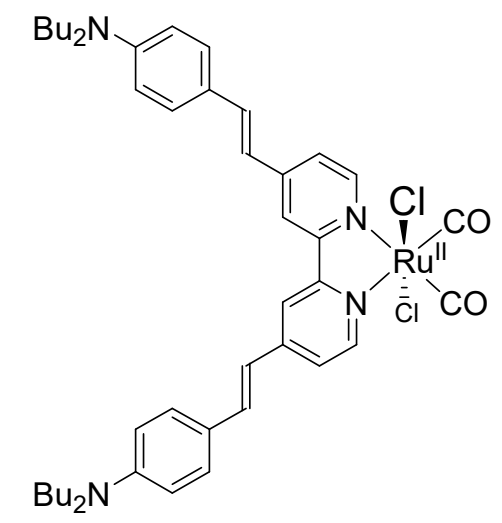

$$
\beta=42010^{-30} \mathrm{~cm}^{5} \mathrm{esu}^{-1}(\text { at } 1.32 \mu \mathrm{m})
$$

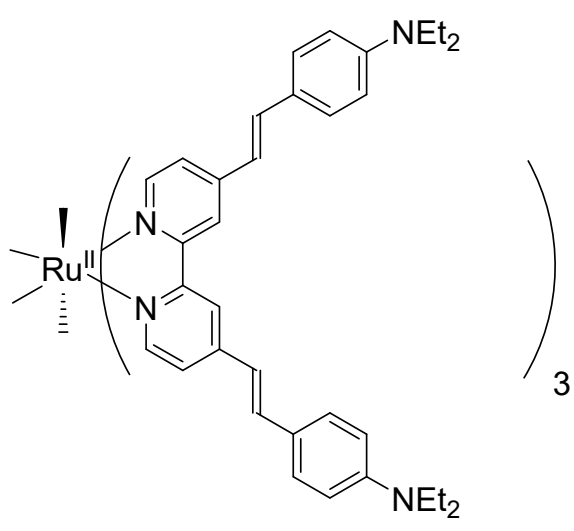

$$
\beta_{0}=30010^{-30} \mathrm{~cm}^{5} \mathrm{esu}^{-1}
$$

Figure 1: Metal organic chromophores with sizeable experimental quadratic NLO response in dipolar (top) [31] and octupolar (bottom) [32] geometries.

It is worth pointing out that the computed $v \mathrm{NO}$ frequencies appear larger than experimental data [33], a discrepancy which has to be related to the modest accuracy of the computational method. Nevertheless, comparing the differences in frequencies instead of the absolute values is more reliable in this case. 
Owing to the crude tendency observed in the Figure, the $\beta$ values of compounds 6 and 8 should lie in the $1000-2000 \times 10^{-30} \mathrm{~cm}^{5} \mathrm{esu}^{-1}$ range. Therefore, the large computed values $(>$ $2500 \times 10^{-30} \mathrm{~cm}^{5} \mathrm{esu}^{-1}$ ) strongly suggest that the properties cannot be fully understood within the framework of the simplified two-level model in these species.

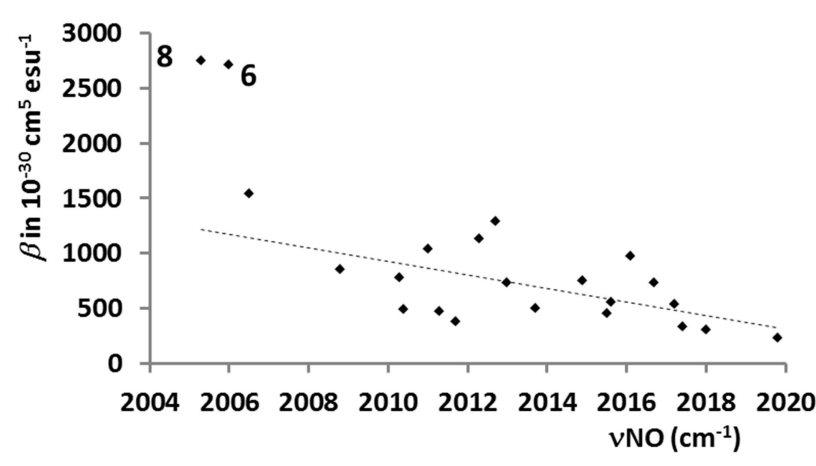

Figure 2. $\beta$ values against $v \mathrm{NO}$ frequencies for the series of 1-22 derivatives. $\mathbf{6}$ and $\mathbf{8}$ are excluded for the computation of the trend (dotted) line.

Finally, and to propose a rational for very large $\beta$ values in some of the present isomers, it may be pointed out that the most efficient of them are those in which the $14 \pi$ electrons are necessarily involved in the path of delocalization. This is exemplified in Scheme 4 for complexes $10\left(\beta=1130 \times 10^{-30} \mathrm{~cm}^{5} \mathrm{esu}^{-1}\right)$, and $11\left(\beta=732 \times 10^{-30} \mathrm{~cm}^{5} \mathrm{esu}^{-1}\right)$, which contain the same $\mathrm{R}$ isomer, and accepting moieties, but differ from the position of the linkage. While the only path of delocalization involves the $14 \pi$-electrons in $\mathbf{1 0}$, a shorter possibility occurs in 11 in which only $10 \pi$ - electrons contribute to the mesomeric equilibrium (bottom of Scheme 4).

Interestingly, the only complexes in which the whole $\pi$-electrons of the $\mathrm{R}$ donating substituents (Scheme 3) are necessarily involved in the path of delocalization are $\mathbf{6 , 7 , 8}$, and $\mathbf{1 0}$. They correspond to the species associated to the highest $\beta$ values, which suggests that this is probably a key electronic parameter to account for their enhanced capabilities.

10

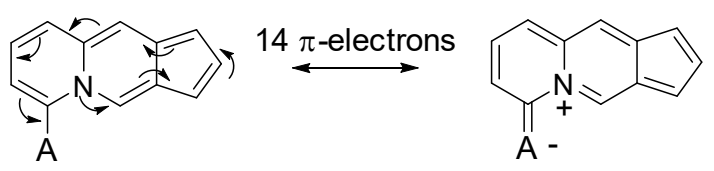

11
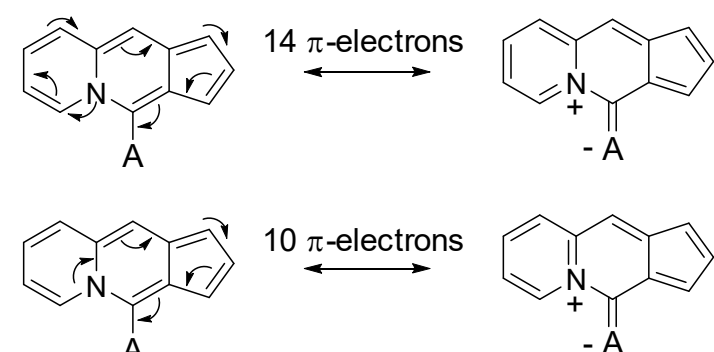

$10 \stackrel{\pi \text {-electrons }}{\longleftrightarrow}$

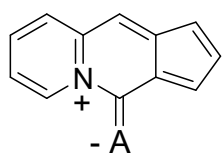

Scheme 4: Possibilities for mesomeric equilibrium between the nitrogen rich donor and the accepting (A) moieties in $\mathbf{1 0}$ and $\mathbf{1 1 .}$

Additionally, the $\beta_{0}$ values associated to the contribution of the dominant transitions of 1-22 are gathered in Table 2. In most cases, a single and low-lying HOMO $\rightarrow$ LUMO based transition leads to a significant $\beta_{0}$, as anticipated in most push-pull organic chromophores [20]. Nevertheless, a second transition is involved in complexes 2, 12, 19, 20, and 22, however with a reduced weight, except in the case of $\mathbf{2 0}$, where 
two transitions $(0 \rightarrow 1$ and $0 \rightarrow 7)$ leads to the same $\beta_{0}$ value.

At this stage, the issue of a correlation between $\beta$ and the dominant $\beta_{0}$ arises naturally, in an attempt to provide a simple picture of the quadratic NLO response. $\beta$ is drawn against $\beta_{0}$ in Figure 3. Asserting that $\beta_{0}$ scales like $\beta$ would far be excessive. Nevertheless, there is a rough tendency, for larger $\beta_{0}$ values in the case of larger $\beta$ value, except in compound 6. The parameters used in the computation of $\beta_{0}$ (equation 6) are gathered in Table 3.

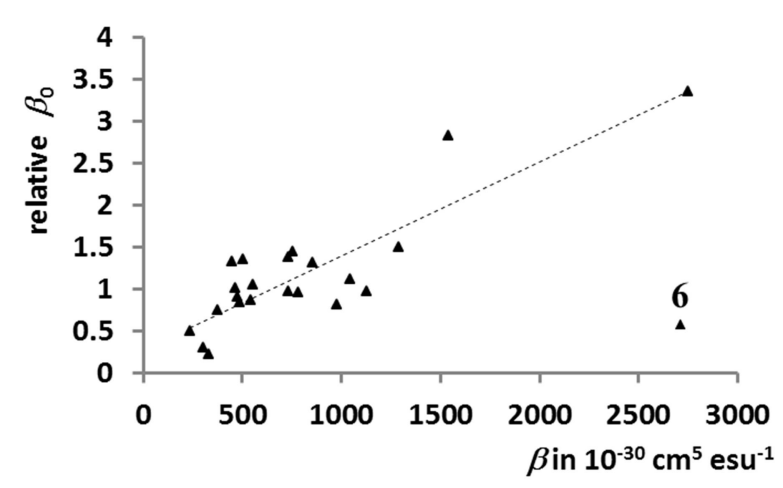

Figure 3. Relative $\beta_{0}$ against $\beta$ for $\mathbf{1 - 2 2}$ and B' (Note that 6 is excluded for the computation of the trend (dotted) line).

Finding $\lambda_{\max }$ values in the $500-1000$ $\mathrm{nm}$ range is fully acceptable in push-pull molecules with delocalization over the whole extend of a chain containing more than $20 \pi$ electrons. Nevertheless, $\lambda_{\max }$ values larger than $2000 \mathrm{~nm}(\mathbf{6}$ and 8) are rather surprising. The fact that they are associated to transitions of unusually weak intensity (8) or unusually reduced $\mu_{\mathrm{ee}}-\mu_{\mathrm{gg}}$ value (6) makes these species definitely unconventional. It raises the issue of the synthetic feasibility of such species in order to clarify experimentally whether or not these unexpected properties are true.

Quadratic $(\beta)$ against cubic $\left(\sigma_{T P A}\right)$ properties

The $\sigma_{\text {TPA }}$ cross-sections of the 22 derivatives are gathered in Table 1, as the relative $\sigma_{\mathrm{TPA}}$ compared to that of $\mathbf{B}^{\prime}$ as a reference. Experimentally, the only reported cross-section in this class of ruthenium nitrosyl complexes is that of $B$ (Scheme 1) with a value of $100+/-13$ GM [34].

The examination of the data leads to the first conclusion that, in spite of their donating capabilities, the heterocyclic amines do not enhance the $\sigma_{\text {TPA }}$ values with respect to that of the fluorenyl-based B' reference. More generally, there is no correlation between $\sigma_{\mathrm{TPA}}$ and $\beta_{0}$.

Additionally, it can be observed in Table 1 that, when two low-lying intense transitions are present (compounds $2, \mathbf{1 2}, \mathbf{1 9}, \mathbf{2 0}, \mathbf{2 2}$ ), the lowest energy transition is associated to the highest $\beta_{0}$ value. This is not the case for $\sigma_{\mathrm{TPA}}$ where the highest energy transition appears to be that of larger cross-section, except in $\mathbf{1 2}$. This difference points out the versatility of the energy as a key parameter in the prediction of the NLO properties. 
Table 3 Dominant transition for $\beta_{0}$ : absorption maxima $\left(\lambda_{\max }\right)$ in $\mathrm{nm}$, intensity $(f), \mu_{\mathrm{ee}}-\mu_{\mathrm{gg}}$ in $\mathrm{D}$, and composition of the configuration interaction.

\begin{tabular}{|c|c|c|c|c|c|}
\hline Compound & transitions & $\lambda_{\max }$ & $f$ & $\mu_{\mathrm{ee}}-\mu_{\mathrm{gg}}$ & composition \\
\hline 1 & $0 \rightarrow 1$ & 581 & 1.14 & 8.22 & HOMO $\rightarrow$ LUMO (87 \%) \\
\hline 2 & $0 \rightarrow 1$ & 623 & 0.46 & 19.2 & HOMO $\rightarrow$ LUMO (83\%) \\
\hline 3 & $0 \rightarrow 1$ & 578 & 0.70 & 21.7 & $\mathrm{HOMO} \rightarrow \mathrm{LUMO}(82 \%)$ \\
\hline 4 & $0 \rightarrow 1$ & 569 & 1.18 & 9.17 & $\mathrm{HOMO} \rightarrow \mathrm{LUMO}(85 \%)$ \\
\hline 5 & $0 \rightarrow 1$ & 662 & 0.76 & 13.5 & HOMO $\rightarrow$ LUMO (76 \%) \\
\hline 6 & $0 \rightarrow 1$ & 2183 & 0.12 & 1.07 & HOMO $\rightarrow$ LUMO (59 \%) \\
\hline 7 & $0 \rightarrow 1$ & 824 & 0.96 & 11.7 & $\mathrm{HOMO} \rightarrow \mathrm{LUMO}(84 \%)$ \\
\hline 8 & $0 \rightarrow 1$ & 2236 & 0.06 & 10.9 & $\mathrm{HOMO} \rightarrow \mathrm{LUMO}(85 \%)$ \\
\hline 9 & $0 \rightarrow 1$ & 727 & 0.07 & 22.9 & HOMO $\rightarrow$ LUMO (77 \%) \\
\hline 10 & $0 \rightarrow 1$ & 881 & 0.45 & 6.84 & HOMO $\rightarrow$ LUMO (83\%) \\
\hline 11 & $0 \rightarrow 1$ & 896 & 0.32 & 13.3 & $\mathrm{HOMO} \rightarrow$ LUMO (67 \%) \\
\hline 12 & $0 \rightarrow 3$ & 496 & 0.39 & 22.7 & $\mathrm{HOMO} \rightarrow$ LUMO (80 \%) \\
\hline 13 & $0 \rightarrow 1$ & 699 & 0.67 & 13.9 & $\mathrm{HOMO} \rightarrow$ LUMO (80 \%) \\
\hline 14 & $0 \rightarrow 1$ & 555 & 1.14 & 8.43 & HOMO $\rightarrow$ LUMO (87 \%) \\
\hline 15 & $0 \rightarrow 1$ & 709 & 0.38 & 13.9 & $\mathrm{HOMO} \rightarrow$ LUMO (80 \%) \\
\hline 16 & $0 \rightarrow 1$ & 603 & 0.68 & 15.6 & $\mathrm{HOMO} \rightarrow$ LUMO (80 \%) \\
\hline 17 & $0 \rightarrow 1$ & 920 & 0.13 & 20.8 & $\mathrm{HOMO} \rightarrow$ LUMO (74 \%) \\
\hline 18 & $0 \rightarrow 1$ & 656 & 1.34 & 7.60 & HOMO $\rightarrow$ LUMO (92 \%) \\
\hline 19 & $0 \rightarrow 1$ & 919 & 0.41 & 6.50 & $\mathrm{HOMO} \rightarrow$ LUMO (67 \%) \\
\hline \multirow[t]{2}{*}{20} & $0 \rightarrow 1$ & 999 & 0.03 & 13.9 & $\mathrm{HOMO} \rightarrow$ LUMO (78 \%) \\
\hline & $0 \rightarrow 7$ & 514 & 0.30 & 11.8 & HOMO-1 $\rightarrow$ LUMO (73 \%) \\
\hline 21 & $0 \rightarrow 1$ & 756 & 0.68 & 11.1 & $\mathrm{HOMO} \rightarrow$ LUMO (87 \%) \\
\hline 22 & $0 \rightarrow 1$ & 822 & 0.59 & 9.77 & $\mathrm{HOMO} \rightarrow$ LUMO $(65 \%)$ \\
\hline B' & $0 \rightarrow 4$ & 464 & 1.21 & 18.4 & HOMO $\rightarrow$ LUMO (79 \%) \\
\hline
\end{tabular}

In push-pull species, the fact that $\beta$ rather unaffected by the presence of the varies as $1 / E^{3}$ leads to the expectation of substituent [15]. By contrast, $\mathrm{R}$ provides the efficient NLO effects restricted to the contribution of the $1^{\text {st }}(\mathrm{HOMO} / \mathrm{LUMO}-$ based $)$ excited state. In the $\left[\mathrm{R}-\mathrm{T}-\mathrm{Ru} \mathrm{u}^{\mathrm{II}}(\mathrm{Cl})_{2}(\mathrm{NO})\right]^{+}$ main contribution to the HOMO level. This is illustrated in Figure 4.

The HOMO energy level appears to be complexes built up from R-donor substituted terpyridines (e.g. $\mathbf{A}$ and $\mathbf{B})$, the electron densities at the LUMO level are mostly located on the $\mathrm{Ru}(\mathrm{NO})$ moieties and therefore, are and hence the highest the $\beta$ value. 
It may be interesting to compare the

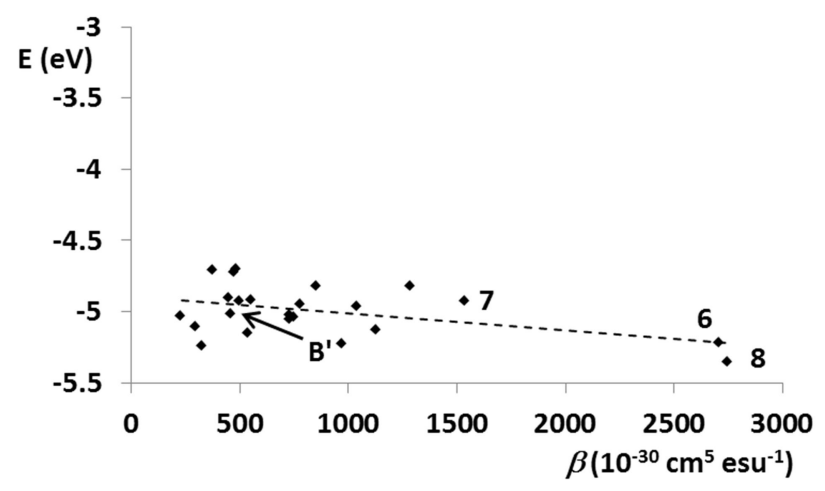
Gibbs free energies $\left(\Delta \mathrm{G}^{\circ}\right)$ of these systems in relation to their $\beta$ values (Figure 5).
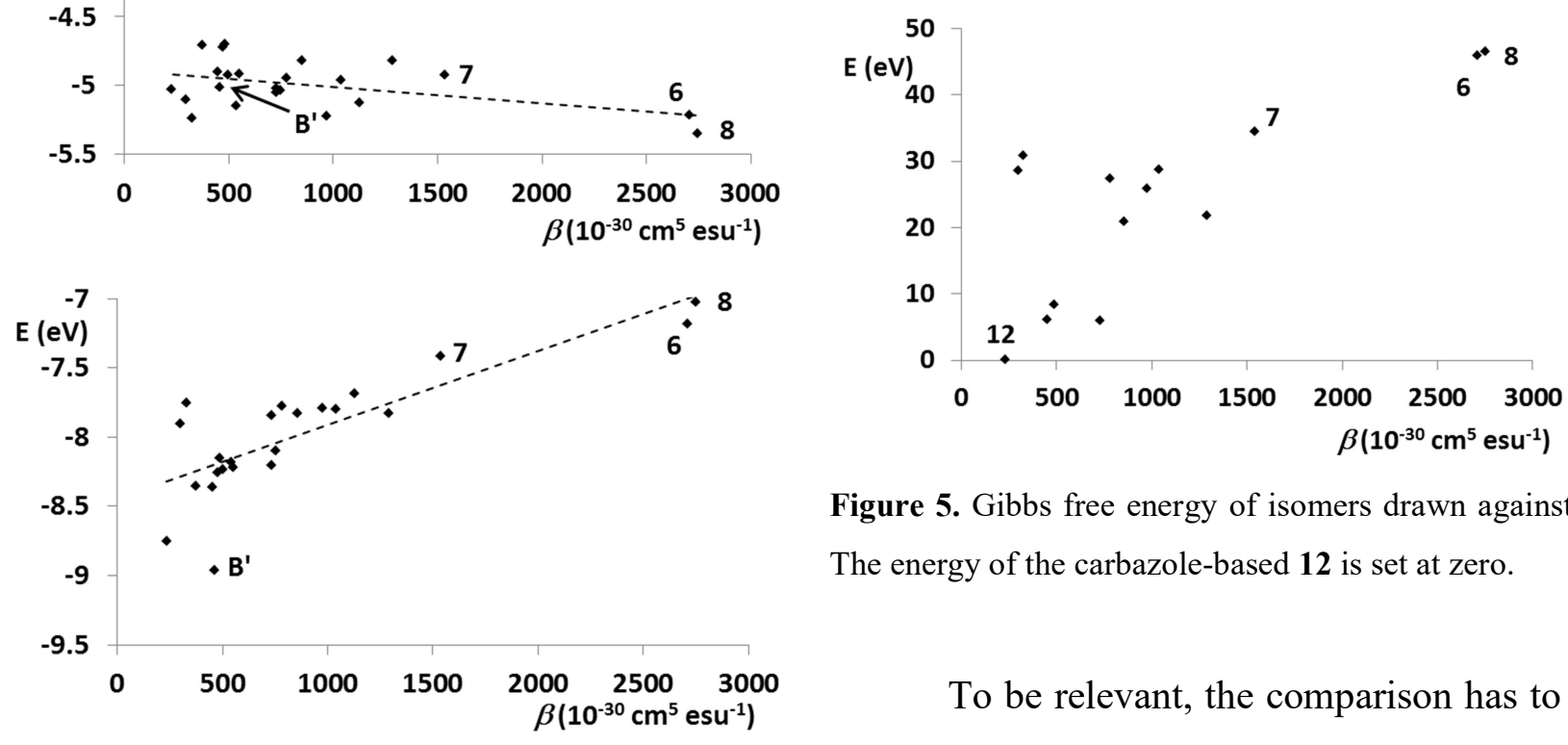

Figure 5. Gibbs free energy of isomers drawn against $\beta$. The energy of the carbazole-based $\mathbf{1 2}$ is set at zero.

To be relevant, the comparison has to be

Figure 4. HOMO (bottom) and LUMO (top) energy levels of 1-22 drawn against $\beta$ and compared to $\mathbf{B}^{\prime}$.

By contrast, the requirement for lowenergy transition appears much less pressing in $\sigma_{\text {TPA }}$. Indeed, in the case of compounds $\mathbf{2}, \mathbf{1 2}$, 19, 20, and 22, where two low-lying intense transitions are present, the trend is that the second transition leads to higher $\sigma_{\mathrm{TPA}}$ value. In Table 3, the only parameter which varies as $\sigma_{\text {TPA }}$ within a given molecule is the oscillator strength $f$, which leads to the conclusion that, in push-pull species, the two-photon absorption spectrum should be reminiscent of the onephoton absorption. Nevertheless, determining precisely the full extent of $\sigma_{\text {TPA }}$ within a series of related molecules (e.g. 1-22) remains a very carried out on molecules having the same formula, which are here the molecules in which -NH was replaced by -NMe (see section titled Selection of the candidates). It appears that, while the carbazole-based compound $\mathbf{1 2}$ is the more stable, the most efficient materials $(\mathbf{8}, \mathbf{6}$, and 7) correspond to the most unstable species. In order to find a simple rationale to account for the relative instability of molecules such as 6, 7, 8, the examination of Scheme 3 shows that they possess no aromatic sextets, by contrast to the stable species 12, which possesses 2 of them. The resulting lack of stabilization suggests how challenging their synthesis might be. Although this question falls obviously out of the scope of the present paper, it will be briefly addressed in conclusion.

challenging issue. 


\section{Synthetic feasibility of 1-22}

The prediction of extremely large $\beta$ values in some of the isomers under investigation within the 1-22 series raises the issue of their synthetic feasibility. This should likely depend on the availability of the heterocyclic amine system (R) and the possibility of its modification for further coupling with the terpyridine moiety. To reach these target species, several strategies are currently being the subject of intense investigation, notably indenopyridines (17-22) [35], isoindoles (1) and pyridoisoindoles (1314) [36]. A literature survey reveals that the cyclopentaquinolines species precursors of molecules 6-8 were never approached, either theoretically or experimentally.

Introducing a halogen atom or triflate fragment into heterocyclic amine with the purpose of allowing a Heck coupling with 4'vinyl-terpyridine will be reliably a way to the formation of the desired ligand. The synthesis of ruthenium-nitrosyl complexes can be performed utilizing the procedure described earlier by Nagao et al [37].

\section{Conclusion}

Depending on the structure of the selected isomer, the twenty two derivatives 1-22 are predicted to possess very different first order $(\beta)$ and second-order (TPA cross-section) properties. They are expected to exhibit a TPA cross-section significantly reduced versus that of the reference B' derivative. By contrast, they should lead to extremely large quadratic hyperpolarizabilities $(\beta)$ in some case. Nevertheless, the most promising systems correspond to the isomers of higher energy, thus point out the challenging issue of their synthetic availability.

\section{Acknowledgements}

Valerii Bukhanko thanks the French/Ukrainian institution for a grant and Campus France (Europe, 835930K) for financial support.

\section{References}

[1] Göppert-Mayer M. Über elementarakte mit zwei quantensprüngen, Ann. Phys. 1931, 401, 273294.

[2] Kauser W, Garret CGB. Two-photon excitation in CaF 2: Eu 2+. Phys. Rev. Lett. 1961, 7, 229231.

[3] Pawlicki M, Collins HA, Denning RG, Anderson HL. Two-photon absorption and the design of two-photon dyes. Angew. Chem. 2009, 48, 3244-3266.

[4] Andraud C, Fortrie R, Barsu C, Stéphan O, Chermette H, Baldeck PL. Excitonically coupled oligomers and dendrimers for two-photon absorption. Adv. Polym. Sci. 2008, 214, 149-203.

[5] He GS, Tan L-S, Zheng Q, Prasad PN. Multiphoton absorbing materials: molecular designs, characterizations, and applications. Chem. Rev. 2008, $108,1245-1330$.

[6] Terenziani F, Katan C, Badaeva E, Tretiak S, Blanchard-Desce M. Enhanced two-photon absorption of organic chromophores: theoretical and experimental assessments. Adv. Mater. 2008, 20, 4641-4678. 
[7] Strehmel B, Strehmel V.Two-photon physical, organic, and polymer chemistry: theory, techniques, chromophore design, and applications. Adv. Photochem. 2007, 29, 111-341.

[8] Schmidt R. Photosensitized Generation of Singlet Oxygen. Photochem. Photobiol. 2006, 82, 1161-1177.

[9] Ignarro LJ. Nitric Oxide: Biology and Pathology. Academic Press: San Diego, CA, 2000.

[10] Bonavida B. Nitric Oxide and Cancer: Prognosis, Prevention and Therapy. Springer, 2010.

[11] Rodrigues FP, Carneiro ZA, Mascharak P, Curli C, Da Silva RS. Incorporation of a ruthenium nitrosyl complex into liposomes, the nitric oxide released from these liposomes and HepG2 cell death mechanism. Coord. Chem. Rev. 2016, 306, 701-707.

[12] Ford PC. Photochemical delivery of nitric oxide. Nitric Oxide 2013, 34, 56-64.

[13] Tfouni E, Ramos Truzzi D, Tavares A., Gomes AJ, Elias Figueiredo L, Wagner Franco D. Biologically activity of ruthenium nitrosyl complexes. Nitric Oxide 2012, 26, 38-53.

[14] Fry NL, Mascharak PK. Photoactive Ruthenium Nitrosyls as NO Donors: How To Sensitize Them toward Visible Light. Acc. Chem. Res. 2011, 44, 289-298.

[15] Akl J, Sasaki I, Lacroix PG, Malfant I, Mallet-Ladeira S, Vicendo P, Farfán N, Santillan R. Comparative photo-release of nitric oxide from isomers of substituted terpyridinenitrosylruthenium(II) complexes: experimental and computational investigations. Dalton Trans. 2014, 45, 12721-12733.

[16] Hamblin MR, Demidova TN. Proc. SPIE, Mechanism for Low-Light Therapy 2006, 6140, 614001-614012.

[17] Albota M, Beljonne D, Brédas JL, Ehrich JE, Fu JY, Heikal AA, Hess SE, Kogej T, Levin MD, Marder SR, MacCord-Maughon D, Perry JW, Röckel H, Rumi M, Subbramaniam G, Webb WW, Wu $\mathrm{XL}, \mathrm{Xu} \mathrm{C}$. Design of organic molecules with large two- photon absorption cross sections. Science 1998, 281, 1653-1656.

[18] Sanz Garcia J, Alary F, Boggio-Pasqua M, Dixon IM. Heully JL. Is photoisomerization required for NO photorelease in ruthenium nitrosyl complexes? J Mol Model. 2016, 22:284(DOI 10.1007/s00894-0163138-2).

[19] (a) Oudar JL, Chemla J. Hyperpolarizabilities of the nitroanilines and their relations to the excited state dipole moment. J. Chem. Phys. 1977, 66, 2664-2668. (b) Oudar JL. Optical nonlinearities of conjugated molecules. Stilbene derivatives and highly polar aromatic compounds. J. Chem. Phys. 1977, 67, 446-457.

[20] Prasad PN, Williams DJ. Introduction to NLO effects in molecules and polymers. New-York:

John Wiley \& Sons, Inc. 1991, chapter 5 and 7.

[21] Kovtunenko VA, Voitenko ZV, Sheptun VL, Tyltin AK, Chernega AI, Struchkov YT, Babichev FS. Comparative analysis of the electronic structure of positional isomers: Indole-isoindole Khimiya Geterotciklicheskih soedinenij, 1984, 11, 1497-1503.

[22] Juric A. J. Heterocyclic Chem., 1984, 21, 273-282. J. Heterocyclic Chem., 1984, 21, 273-282.

[23] Kovtunenko VA, Voitenko ZV, Sheptun VL, Savranskiy LI, Tyltin AK, Babichev FS. The electronic structure of azinoisoindoles with the node nitrogen atom. Ukrainskiy Chimicheskiy J. 1985, 51, 976-987.

[24] Gaussian 09, Revision E.01, Frisch M J, Trucks GW, Schlegel HB, Scuseria GE, Robb MA, Cheeseman JR, Scalmani G, Barone V, Mennucci B, Petersson GA, Nakatsuji H, Caricato M, Li X, Hratchian HP, Izmaylov AF, Bloino J, Zheng G, Sonnenberg JL, Hada M, Ehara M, Toyota K, Fukuda R, Hasegawa J, Ishida M, Nakajima T, Honda Y, Kitao O, Nakai H, Vreven T, Montgomery JA Jr, Peralta JE, Ogliaro F, Bearpark M, Heyd JJ, Brothers E, Kudin KN, Staroverov VN, Kobayashi R, Normand J, Raghavachari K, Rendell A, Burant JC, Iyengar SS, Tomasi J, Cossi M, Rega N, 
Millam JM, Klene M, Knox JE, Cross JB, Bakken V, Adamo C, Jaramillo J, Gomperts R, Stratmann RE, Yazyev O, Austin AJ, Cammi R, Pomelli C, Ochterski JW, Martin RL, Morokuma K, Zakrzewski VG, Voth GA, Salvador P, Dannenberg JJ, Dapprich S, Daniels AD, Farkas Ö, Foresman JB, Ortiz JV, Cioslowski J, Fox DJ, Gaussian, Inc., Wallingford CT, 2009.

[25] (a) Hay PJ, Wadt WR. Ab initio effective core potentials for molecular calculations. Potentials for the transition metal atoms Sc to $\mathrm{Hg}$. J. Chem. Phys. 1985, 82, 270-283. (b) Wadt WR, Hay PJ. $\mathrm{Ab}$ initio effective core potentials for molecular calculations. Potentials for main group elements $\mathrm{Na}$ to $\mathrm{Bi}$. J. Chem. Phys. 1985, 82, 284-298. (c) Hay PJ, Wadt WR. $\mathrm{Ab}$ initio effective core potentials for molecular calculations. Potentials for $\mathrm{K}$ to $\mathrm{Au}$ including the outermost core orbitals. J. Chem. Phys. 1985, 82, 299310 .

[26] Rose MJ, Mascharak PK. Photosensitization of Ruthenium nitrosyl to red light with an isoelectronic series of heavy-atom chromophores: experimental and density functional theory studies on the effects of O-, S-, and Se-substituted coordinated dyes. Inorg. Chem. 2009, 48, 6904-6917.

[27] Hirva P, Haukka M, Jaconen M. DFT tests for group 8 transition metal carbonyl complexes. J. Mol. Model. 2008, 14, 171-181.

[28] Kleinman DA. Nonlinear dielectric polarization in optical media. Phys. Rev. 1962, 126, $1977-$ 1979.

[29] Morley JO, Pugh D. Computational evaluation of second-order optical nonlinearities. In: Nalwa HS, Miyata S, editors. Nonlinear optics of organic molecules and polymers. CRC press Boca Raton; 1997. p. 29-56.

[30] Ducere JM, Lepetit Ch, Lacroix PG, Heully JL, Chauvin R. Quadratic hyperpolarizability of carbomeric structures. Chem. Mater. 2002, 14, 33323338 .
[31] Vance FW, Hupp JT. Probing the Symmetry of the Nonlinear Optic Chromophore Ru(trans-4,4 diethylaminostyryl-2,2'-bipyridine) $33^{2+}$ : Insight from Polarized Hyper-Rayleigh Scattering and Electroabsorption (Stark) Spectroscopy. J. Am. Chem. Soc., 1999, 121, 4047-4053.

[32] Dhenaut C, Ledoux I, Samuel IDW, Zyss J, Bourgault M, Le Bozec H. Chiral metal complexes with large octupolar optical nonlinearities. Nature 1995, 374, 339-340.

[33] (a) da S. S. Borges D, Davanzo CU, Castellano EE, Z-Schpector J, Silva SC, Franco DW. Ruthenium nitrosyl complexes with N-heterocyclic ligands. Inorg. Chem. 1998, 37, 2670-2677 and references herein. (b) Cormary B, Ladeira S, Jacob K, Lacroix PG, Woike Th, Schaniel D, Malfant I. Structure influence on the Photochromic response of a series of ruthenium mononitrosyl complexes. Inorg. Chem. 2012, 51, 74927501.

[34] Enriquez-Cabrera A, Sasaki I, Bukhanko V, Tassé M, Mallet-Ladeira S, Lacroix PG, Barba-Barba RM, Ramos G, Farfán Voitenko Z, Malfant I. Replacing two Chloride Anions by a Bipyridine in Ruthenium Nitrosyl (NO) Complexes with NO Release Capabilities: a Comparative Study. Eur. J. Inorg. Chem. accepted.

[35] Shakibaei GI, Bazgir A. A highly efficient one-pot synthesis of indenopyridine-fused spirocyclic systems. RSCAdv. 2016, 6, 22306-22311.

[36] Pokholenko, AA, Voitenko ZV, Kovtunenko VA. Pyrido- and pyrimido-isoindoles: methods of synthesis and properties, Russ. Chem. Rev. 2004, 73, 771-784.

[37] Nagao H, Enomoto K, Wakabayashi Y, Komiya G, Hirano T, Oi T. Synthesis of nitrosylruthenium complexes containing 2,2':6',2', terpyridine by reactions of alkoxo complexes with acids. Inorg. Chem., 2007, 46. 1431-1439. 